\title{
Analysis of Students' Alternative Conceptions about Electrolyte and Non-Electrolyte Solutions Using a Two-Tier Diagnostic Test for Chemistry Teaching Improvement
}

\author{
Tritiyatma Hadinugrahaningsih*, Rahma Esi Andina, Lingga Restu Munggaran, Yuli Rahmawati \\ Department of Chemistry Education, Faculty of Mathematics and Sciences, Universitas Negeri Jakarta, Indonesia
}

Received February 17, 2020; Revised March 20, 2020; Accepted March 28, 2020

Copyright $\bigcirc 2020$ by authors, all rights reserved. Authors agree that this article remains permanently open access under the terms of the Creative Commons Attribution License 4.0 International License

\begin{abstract}
This research explores students' alternative conceptions about electrolyte and non-electrolyte solutions. Data collection was carried out using a two-tier diagnostic test and in-depth interviews. Ten questions of a two-tier diagnostic test were validated using item validation and construct validation. The result of this research showed that $18,31 \%$ of students had alternative conceptions about electrolyte and non-electrolyte solutions, 16,54\% students had alternative conceptions chemical bonding and its impact on electricity, and $16,01 \%$ students had alternative conceptions about the phase of a compound and its impact on electricity. This result indicates that students' alternative conceptions can be obtained through students' experiences and observations, the term used by the teacher and students, the book, or the way students develop their knowledge. The finding of this research provides teachers to know the sources of alternative conceptions that may occur among students, and how to prevent it.
\end{abstract}

Keywords Students' Conceptions, Alternative Conceptions, Electrolyte Solution, Two-Tier Diagnostic Test

\section{Introduction}

Chemistry is an essential basis for many facets of our everyday lives, and has many potential benefits for our future. An understanding of chemistry allows students to make sense of and explain the world around them [1]. In chemistry learning, students are expected to understand chemistry concepts in order to solve problems through building their individual knowledge [2], [3]. Therefore, the overall objective of chemistry education is to help students to construct a meaningful understanding of the nature of matter and changes in matter [4]. Chemistry has been regarded as a difficult subject by chemistry teachers, researchers, and educators. Chemical concepts were described in three different representations, which are microscopic, submicroscopic, and symbolic representations [5]. Most students considered that chemistry is difficult to understand because of their lack in understanding about the three levels of representation in chemistry. It is now generally agreed that students bring with them to science lessons certain ideas and notions that are well established in their ways of thinking but are inconsistent with the ideas of teachers and scientists [6]. These interpretations which are called misconceptions or alternative conceptions and influence how students learn new scientific knowledge play an essential role in subsequent learning [7]. In this paper we will use the term 'alternative conceptions' to mean a conception which differs significantly from that which is socially agreed to by the scientific community [8], [9].

Most of students had a different conception about chemistry, one of which is electrolyte and non-electrolyte concept. This is in accordance with previous research which found that students considered that electrons can flow through aqueous solutions without assistance from the ions [10]; Electrons move through solution by being attracted from one ion to the other [11]. The concept that is not in accordance with scientific concepts is called alternative concept. Students' understanding cannot be easily measured or observed. Teachers need to probe students' understanding before and after instruction [12]. Teachers need to learn to apply alternative assessment methods for supporting learning in the classroom that can build self-regulated learning and students' confidence, rather than destroy their self-esteem as learners [13]. One way to tackle this problem is to use two-tier multiple 
choice questions, which require students to select both the correct answer and its reason [14], [15]. The use of a two-tier diagnostic tests has provided a better way to improve how students' conceptions can be evaluated [6]. Two-tier diagnostic test, as Treagust reported, was first developed with items specifically designed to identify alternative conceptions and misunderstandings in clearly defined content areas of science [12], [14]. Two-tier diagnostic tests have been regarded as an effective assessment tool to determine students' conceptual understanding and alternative conceptions [6], [12], [16]. In a two-tier test, the first tier asks a student to make a choice about some specific content knowledge and the second tier asks the students about the reason or explanation for his or her choice in the first tier. In Treagust's (1988) method for scoring of two-tier items, each item was considered to be correctly answered if a student's choice of the first tier (content knowledge) and the second tier (reason for the first tier) were both correct. With this stringent method of scoring, chances of obtaining a correct answer by guessing were very low [12]. Students' understanding cannot be easily measured or observed. Teachers need to probe students' understanding. One good method for doing this is by way of interviews [17], [18]. Therefore, besides using two-tier diagnostic tests, students' alternative conceptions about the concept of electrolyte and non-electrolyte solutions are also obtained using in-depth interviews.

In recent years, many studies in the chemical education literature have reported students' alternative conceptions in chemistry and the difficulty they present for future learning [17]. It causes students' understanding to become a major problem in chemistry education. The concepts of electrolyte and non-electrolyte solutions are one of the difficult concepts for students to understand, so many students have alternative conceptions about this concept.
Based on mentioned issues, the objectives of this research were summarized as follows:

1. Analyze students' alternative conceptions about electrolyte and non-electrolyte solutions using two-tier diagnostic test.

2. Provided a better way to improve how student conceptions in chemistry can be evaluated.

\section{Methodology of Research}

This research was conducted by means of a qualitative research. This research was conducted in public school in Karawang, West Java and involved 127 students in the academic year of 2017/2018. These students consisted of first-year students enrolled for science program. Students' understanding was analyzed using two-tier diagnostic test and in-depth interview. This research was executed in 10th grade of senior high school in public school in Karawang, West Java. The result of this research can be used as a reference for teachers to provide a better way to improve how students' conceptions in chemistry can be evaluated.

Learning activities were carried out in two weeks with guided discussion in a small group consisted of six students in a group. At the end of learning, students have to answer ten questions of two-tier multiple diagnostic test, then some students were interviewed to know students' conceptions about electrolyte and non-electrolyte solutions. Interviews involved some students that had chosen randomly. Interviews were conducted using open-ended questions and the writing-drawing technique. Based on test and interview results, some conceptions of students in electrolyte and nonelectrolyte solutions were identified. The questions consisted of three concepts about electrolyte and non-electrolytes and are explained in Table 1 which showed us the parameters of the two-tier diagnostic test.

Table 1. The parameters of the two-tier diagnostic test

\begin{tabular}{|c|c|c|}
\hline Concept & Parameter & Number of Questions \\
\hline \multirow{3}{*}{$\begin{array}{l}\text { Concept of electrolyte solution } \\
\text { and non-electrolyte solution }\end{array}$} & Students can understand the definition of electrolyte solution. & 1 \\
\hline & \multirow{2}{*}{ Students can determine the electricity property of solution based on data. } & 8 \\
\hline & & 10 \\
\hline \multirow{5}{*}{$\begin{array}{l}\text { Chemical bonding and its } \\
\text { impact on electricity }\end{array}$} & $\begin{array}{l}\text { Students can determine the non-electrolyte solution and explain the reason } \\
\text { using its chemical bonding }\end{array}$ & 2 \\
\hline & $\begin{array}{l}\text { Students can determine the electrolyte solution based on data and explain the } \\
\text { reason using the data and its chemical bonding. }\end{array}$ & 4 \\
\hline & $\begin{array}{l}\text { Students can determine the electrolyte solution based on submicroscopic } \\
\text { representation and explain the reason using its chemical bonding. }\end{array}$ & 5 \\
\hline & $\begin{array}{l}\text { Students can determine that } \mathrm{HCl} \text { is an electrolyte solution and explain that } \\
\text { polar covalent bonding can be dissociated. }\end{array}$ & 6 \\
\hline & $\begin{array}{l}\text { Students can determine the compound that can conduct electricity based on } \\
\text { the chemical bonding and explain the reason. }\end{array}$ & 9 \\
\hline \multirow{2}{*}{$\begin{array}{l}\text { Phase of compound and its } \\
\text { impact for electricity }\end{array}$} & $\begin{array}{l}\text { Students can determine electrical property of sodium chloride in solid, } \\
\text { aqueous, and solution and explain the reason. }\end{array}$ & 3 \\
\hline & $\begin{array}{l}\text { Students can determine the compound that can conduct electricity in various } \\
\text { phases and explain the reason. }\end{array}$ & 7 \\
\hline
\end{tabular}


Parameters of the questionnaire showed us the explanation of a two-tier diagnostic test. The two-tier diagnostic test on electrolyte and non-electrolyte solutions consisted of ten questions. Based on construct validity, the questionnaire was validated by six experienced teachers with $\mathrm{v}$ value between $0,95-1,00$ and it showed that all questions in the two-tier diagnostic test were valid. In addition, item validation involved 115 students and obtained a $\Gamma$ value for each item was more than that in the $\Gamma$ table $(0,183)$ and it showed that all items in the two-tier diagnostic test were valid.

\section{Results and Discussions}

\subsection{Result of Two-Tier Diagnostic Test}

The result was obtained from students' answers to two-tier diagnostic test questions involving electrolyte and non-electrolyte solutions. The questionnaire consisted of three concepts in electrolytes and non-electrolytes, concepts of electrolyte and non-electrolyte solutions, chemical bonding and its impact on properties, and phases of compounds and its impact on electrical properties. The consistency of students' answers were also used to find out about the students' understanding [19]. The overall average results for each item are shown in Table 2. In addition, an analysis was conducted to compare the consistency of answers regarding the concept of students' understanding in the three concept categories shown with their responses or their customized reasons for selected the multiple-choice items.
According to the result, in the first concept category (question number 1, 8, 10), students have good understanding of the first question about electrolyte and non-electrolyte concepts. The result from question 1 showed that there is no difference between the classes. Thus, from the questions 8 and 10 there were differences between classes. Students in group IV have the highest percentage of students that answered the questions correctly in the first category $(57,78 \%)$. Students in group II have the lowest percentage of students that answered the questions correctly $(36,46 \%)$. This result showed us that there are differences between the classes in the concept of electrolyte and non- electrolyte solutions, especially for the question 8 and 10. In the second concept (question number 2, 4, 5, 6, and 9), Group I has the lowest students percentage that answered correctly in the concept category of chemical bonding and its impact on electricity properties $(43,23 \%)$. Group IV has the highest students' percentage that answered correctly in the concept category chemical bonding and its impact on electricity properties $(89,24 \%)$. This result showed us that there are differences between the classes in the concept of chemical bonding and its impact on electricity properties. In the third concept (question numbers 3 and 7), Group II has the lowest students' percentage that answered correctly in the concept category phase of compound and its impact on electricity properties $(28,13 \%)$. Group IV has the highest students' percentage that answered correctly in concept category chemical bonding and its impact on electricity properties $(75,00 \%)$. This result showed us that there were differences between the classes in the concept of phase of compound and its impact on electricity properties.

Table 2. Percentage of correct students' answers in the first tier

\begin{tabular}{|c|c|c|c|c|c|c|c|}
\hline \multirow{3}{*}{ No. } & \multirow{3}{*}{ Concept Categories } & \multirow{3}{*}{$\begin{array}{l}\text { Question } \\
\text { Number }\end{array}$} & \multicolumn{4}{|c|}{ Student's Group } & \multirow{3}{*}{$\begin{array}{c}\text { Total } \\
\mathbf{N}=\mathbf{1 2 7}\end{array}$} \\
\hline & & & $\mathbf{I}$ & II & III & IV & \\
\hline & & & $\mathbf{N}=\mathbf{3 1}$ & $\mathbf{N}=32$ & $\mathbf{N}=32$ & $\mathbf{N}=\mathbf{3 0}$ & \\
\hline \multirow{4}{*}{1} & \multirow{4}{*}{$\begin{array}{c}\text { Concept of electrolyte and non-electrolyte } \\
\text { solutions }\end{array}$} & 1 & 100,00 & 96,88 & 100,00 & 100,00 & 99,20 \\
\hline & & 8 & 12,90 & 6,25 & 25,00 & 36,67 & 21,30 \\
\hline & & 10 & 35,48 & 6,25 & 9,38 & 36,67 & 22,80 \\
\hline & & Mean & 49,46 & 36,46 & 44,79 & $\mathbf{5 7 , 7 8}$ & 47,77 \\
\hline \multirow{6}{*}{2} & \multirow{6}{*}{$\begin{array}{c}\text { Chemical bonding and its impact on electrolyte } \\
\text { properties }\end{array}$} & 2 & 38,70 & 53,10 & 78,10 & 96,20 & 66,90 \\
\hline & & 4 & 58,10 & 90,60 & 100,00 & 86,70 & 84,30 \\
\hline & & 5 & 9,68 & 6,25 & 59,40 & 100,00 & 44,10 \\
\hline & & 6 & 93,55 & 96,90 & 100,00 & 93,30 & 96,10 \\
\hline & & 9 & 16,13 & 78,10 & 78,10 & 70,00 & 61,40 \\
\hline & & Mean & 43,23 & 64,99 & 83,12 & 89,24 & 70,56 \\
\hline \multirow{3}{*}{3} & \multirow{3}{*}{$\begin{array}{l}\text { Phase of compound and its impact on electrolyte } \\
\text { properties }\end{array}$} & 3 & 54,84 & 50,00 & 68,80 & 90,00 & 66,10 \\
\hline & & 7 & 12,90 & 6,25 & 18,80 & 60,00 & 25,20 \\
\hline & & Mean & $\mathbf{3 3 , 8 7}$ & 28,13 & 43,80 & 75,00 & 45,65 \\
\hline
\end{tabular}


Table 3. Percentage of consistent students' answers

\begin{tabular}{|c|c|c|c|c|c|c|c|}
\hline \multirow{3}{*}{ No. } & \multirow{3}{*}{ Concept Categories } & \multirow{3}{*}{$\begin{array}{l}\text { Question } \\
\text { Number }\end{array}$} & \multicolumn{4}{|c|}{ Student's Group } & \multirow{3}{*}{$\begin{array}{r}\text { Total } \\
\mathbf{N}=127\end{array}$} \\
\hline & & & I & II & III & IV & \\
\hline & & & $\mathbf{N}=\mathbf{3 1}$ & $\mathbf{N}=32$ & $\mathrm{~N}=32$ & $\mathbf{N}=\mathbf{3 0}$ & \\
\hline \multirow{4}{*}{1} & \multirow{4}{*}{$\begin{array}{l}\text { Concept of electrolyte and non- electrolyte } \\
\text { solutions }\end{array}$} & 1 & 48,00 & 69,00 & 62,50 & 80,00 & 65,35 \\
\hline & & 8 & 3,00 & 3,00 & 18,75 & 23,33 & 13,39 \\
\hline & & 10 & 13,00 & 0,00 & 3,13 & 20,00 & 10,24 \\
\hline & & Mean & 21,33 & 24,00 & 28,13 & 41,11 & 29,66 \\
\hline \multirow{6}{*}{2} & \multirow{6}{*}{$\begin{array}{l}\text { Chemical bonding and its impact on electrolyte } \\
\text { properties }\end{array}$} & 2 & 13,00 & 44,00 & 62,50 & 66,67 & 46,46 \\
\hline & & 4 & 35,00 & 81,00 & 15,63 & 50,00 & 45,67 \\
\hline & & 5 & 6,00 & 3,00 & 37,50 & 90,00 & 33,86 \\
\hline & & 6 & 19,00 & 94,00 & 40,63 & 53,33 & 51,18 \\
\hline & & 9 & 0,00 & 9,00 & 25,00 & 46,67 & 21,26 \\
\hline & & Mean & 14,60 & 46,20 & 36,25 & 61,33 & 39,69 \\
\hline \multirow{3}{*}{3} & \multirow{3}{*}{$\begin{array}{l}\text { Phases of compound and its impact on electrolyte } \\
\text { properties }\end{array}$} & 3 & 29,00 & 9,00 & 6,25 & 50,00 & 22,83 \\
\hline & & 7 & 3,00 & 3,00 & 6,25 & 50,00 & 18,11 \\
\hline & & Mean & 16,00 & 6,00 & 6,25 & 50,00 & 20,47 \\
\hline
\end{tabular}

Besides students' answers in the first tier of the two-tier diagnostic test, consistency in students' understanding of the three categories of concepts was evaluated. The two-tier diagnostic test is also used to evaluate students' responses in the first tier. Based on the analysis, students are not very consistent in understanding the key concepts. According to the results, we can know that students' ability to answer the first tier in the two-tier diagnostic test of electrolyte and non-electrolyte solutions was different between the classes. The lowest percentage was obtained by group II in the concept phase and its impact on electricity properties $(28,13 \%)$ and the highest percentage was obtained by group IV in the concept phase and its impact on electricity properties $(75,00 \%)$. The consistency of the answers of students was analyzed to gain students' conception in electrolyte and non-electrolyte concepts. The consistency of students' answers is shown in Table 3. Based on the table, it is known that some students show consistency of answers of two-tier diagnostic test question. It shows that some students have good concept understanding. Students who answered correctly for both tiers showed that the students' had an appropriate conceptual understanding [6], [20], [21]. The result showed us that $21,33 \%$ students in group I, $24,00 \%$ students in group II, $28,13 \%$ students in group III, and $41,11 \%$ students in group IV have a good understanding of the concept in electrolyte and non-electrolyte concept.

An electrolyte solution is a solution that has the ability to conduct electricity suggesting the presence of electrically charged particles that are able to move within the solution [22]. Some students answered correctly the question in the two-tier diagnostic test about electrolyte and nonelectrolyte solutions. Students assumed that ions in solution can move freely through the solution, so electricity can be conducted. This result is in accordance with the previous research. Students assumed that electrons flowing through the electrolyte solutions [11]. This statement based on students' answers and interview results are given below.
"An electrolyte solution is a solution that can conduct electricity because the ions can move freely in a solution"

(Students' Interviews - Student 03, June 02, 2018)

"An electrolyte solution is a solution that can conduct electricity and if decomposed in water, produces positive and negative ions that can move freely"

(Students' Interviews - Student 02, June 02, 2018)

All students who were interviewed have an appropriate concept when explaining the electrolyte concept. Students assumed that the ions in solution cause electrical properties. The compound that cannot dissociate into ions cannot conduct electricity. Students tried to explain the dissociation with the writing and drawing techniques. Students' explanation can be explained in Figure 1 below. The image was a student's representation in the ionization process when a compound dissolved in water and produced ions.

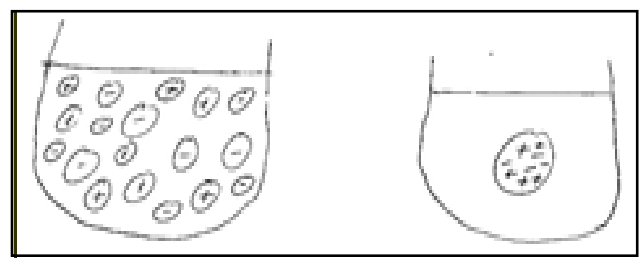

Figure 1. Ionization of Electrolyte Compounds and Non Electrolyte Compounds

The image above explains an electrolyte ionization in solution (right) and a non-electrolyte in solution (left). According to the image, students assumed that a non-electrolyte solution stays as molecules and is not dissociated into ions. This statement is in accordance with the previous research and appropriate with the concepts of electrolyte and non-electrolyte [22], [23]. 

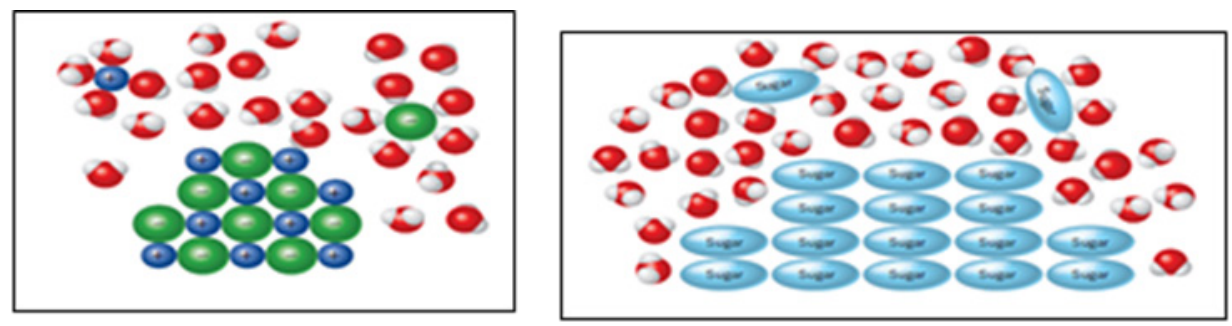

Figure 2. Electrolyte and Non Electrolyted Solution

Based on the image above, non-electrolyte compounds, when dissolved in water, are separated from each other and mingled with the water molecules. The solute molecules stay intact and do not dissociate into smaller particles. When an electrolyte dissolves in water, ions are separate from the solid and become surrounded by water molecules. The ions are said to be hydrated. In the solution, the ions are able to move freely, which enables the solution to conduct electricity [22]. Most of the students have an appropriate concept in explaining electrolyte and non-electrolyte solutions.

Besides the definition of an electrolyte solution, there are questions that students decide the electricity of the compound. Fifty-six students answered correctly when they have to decide on the electrical properties based on a compound's name. Based on the interview results, students experienced difficulty to decide the properties because they have difficulty in compounds nomenclature, so they cannot determine the electrical properties.

"What makes the problem difficult is the nomenclature, so I find it difficult to distinguish electrolyte and non-electrolyte"

\section{(Students' Interview - Student 03, June 02, 2018)}

That statement showed us that students need to have an ability to make a connection with the previous or next concept [24]-[26]. To determine the properties of a solution, students need to use the chemical bonding and nomenclature of compounds concept. The macroscopic representation of an electrolyte solution can be identified from the experiment that uses a battery, lamp, electrodes, and solution. Electrolyte solutions are divided into two, strong electrolyte and weak electrolyte solutions. Based on experiment, a strong electrolyte and a weak electrolyte can be identified from the lamp and gases around the electrodes. Most students can answer correctly the questions about electrolyte properties by the experiment's result. This result is appropriate with the concept that states the presence of ions in aqueous solution by measuring how well the solution conducts electricity.

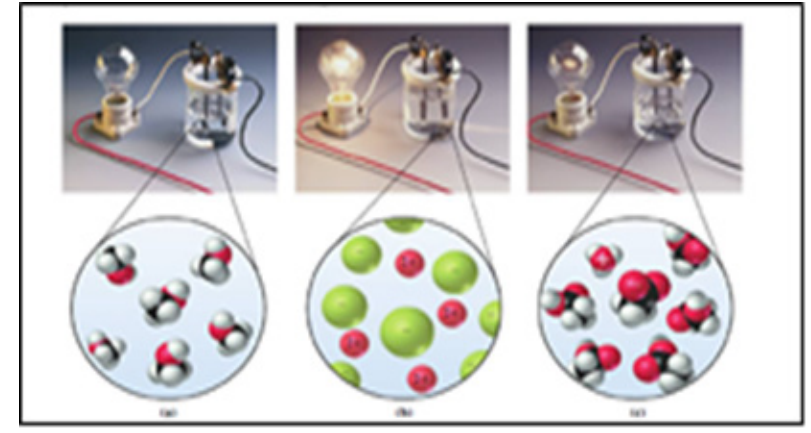

Figure 3. Non-Electrolyte Solution (a), Strong Electrolyte Solution (b), and Weak Electrolyte Solution (c)

Based on the image above, if the lamp fails to light up, so the conclusion is no ions are present (or if some are present, their concentration is extremely low). The solution is either a solution of a non-electrolyte or a very dilute solution of an electrolyte). If the lamp lights up brightly, the conclusion is the concentration of ions in solution is high, so the solute is a strong electrolyte. If the lamp lights up only dimly, the conclusion is ions are present in solution but the concentration of ions is low. The solution could be a solution of a weak electrolyte [22]. According to test results and appropriate concepts, most students have an appropriate concept in using macroscopic representations to decide on the electrical properties of the solution.

In the chemical bonding concept and its impact for electricity properties, $14,60 \%$ of students in group I, $46,20 \%$ students in goup II, 36,25\% students in goup III, and $61,33 \%$ students in group IV have a good understanding about the chemical bonding concept and its impact on electrical properties. The chemical bonding concept has an important role in the electrical properties of solutions [27]. Chemical bonding can explain the dissociation ability of a compound. Students need to understand the chemical bonding concept to explain about electrolyte solutions. Essentially all soluble ionic compounds and only a relatively few molecular compounds are strong electrolytes and most molecular compounds are either nonelectrolytes or weak electrolytes [22]. Based on the two-tier diagnostic test's results, most students have an appropriate concept about chemical bonding and electricity. Most of students can decides that glucose $\left(\mathrm{C}_{6} \mathrm{H}_{12} \mathrm{O}_{6}\right)$ is a non-electrolyte solution that cannot produce ions in aqueous solution. 


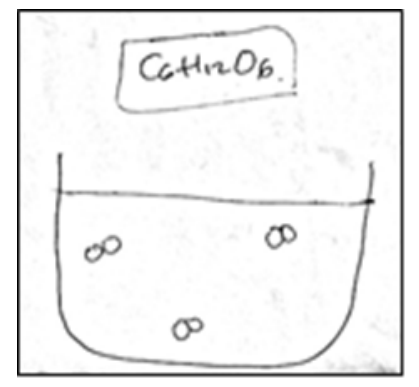

Figure 4. Glucose in aqueous solution

Based on the picture above, glucose in aqueous solution stays as molecules in its solution. Glucose cannot produce ions because glucose has covalent non polar bonds, so the atoms cannot dissociate in its solution. Besides glucose, students also can determine that $\mathrm{HCl}$ was an electrolyte solution. It was because $\mathrm{HCl}$ has covalent polar bonds, so it can be separated into ions in aqueous solution and conduct electricity.

In the third concept, phase and its impact on electricity, $16,00 \%$ of students in group I, $6,00 \%$ in group II, $6,25 \%$ in group III, and $50,00 \%$ students in group III have good understanding. Based on the results, the highest percentage was obtained by group III. The students' ability to answer the questions about phase and its impact on the electrical properties can be caused by the students having a good understanding of the concept of electrolyte and non-electrolyte solutions. Besides the chemical bonding, the phase of the compounds also has an important role in determining electricity properties. Based on the results using the two-tier diagnostic test, most students have an alternative conception about the phase of compounds to determine electrical properties. Most students did not consider the role of phase, they only considered its bonding.
Most of students stated that $\mathrm{HCl}$ is an electrolyte in all phases. This result showed us that the students did not understanding about phase and ions that can conduct electricity. Based on interviews, students evidently knew about the phase. Students knew that "s" is for solid, "aq" is for aqueous, "l" is for liquid, and "g" is for gas. Students knew that sodium chloride in the solid phase cannot be an electrolyte, because no ions can move freely that can conduct electricity.

"Salt in the solid phase cannot conduct electricity because it is not ionic. Salt may be an electrolyte when the salt is dissolved in water"

(Students' Interviews - Student 03, June 02, 2018)

Based on the test result and interview results, it can be known that some students do not really have alternative conception. Students are just not accustomed to using the phase of compounds so they forget about its meaning, especially about electrolyte solutions.

\subsection{Students' Alternative Concept}

Besides the results above, most students have an appropriate conception and some of them have alternative conceptions. Students' alternative conceptions are inconsistent with the scientific conceptions [8], [28], [29]. The alternative conceptions that students have about electrolyte and non-electrolyte concepts were shown in Table 4. Overall, through an analysis of answers to the two-tier diagnostic test, it showed that the students' have limited understanding of the concepts of electrolyte and non-electrolyte solutions, chemical bonding, and phase of a compound and its impact on electricity. 
Table 4. Percentage of student's alternative concept

\begin{tabular}{|c|c|c|c|c|c|c|}
\hline \multirow{2}{*}{ No. } & \multirow{2}{*}{ Students' Alternative Concepts } & Group I & Group II & Group III & Group IV & \multirow{2}{*}{$\begin{array}{c}\text { Total } \\
\mathbf{N}=127\end{array}$} \\
\hline & & $\mathbf{N}=\mathbf{3 1}$ & $\mathbf{N}=\mathbf{3 2}$ & $\mathbf{N}=\mathbf{3 2}$ & $\mathbf{N}=\mathbf{3 0}$ & \\
\hline \multirow{5}{*}{1} & $\begin{array}{l}\text { Electrolyte solution is a solution which can produce charged } \\
\text { compound }\end{array}$ & 29,03 & 15,63 & 25,00 & 13,33 & 20,47 \\
\hline & Electrolyte solution has a large potential difference & 22,58 & 12,50 & 12,50 & 6,67 & 13,39 \\
\hline & Electrolyte solution should be able to turn on the lamp & 9,68 & 43,75 & 34,38 & 20,00 & 26,77 \\
\hline & $\begin{array}{l}\text { Electrolyte solution is a solution which can react in } \\
\text { electrode and produce gasses }\end{array}$ & 22,58 & 6,25 & 6,25 & 16,67 & 12,60 \\
\hline & Mean & 20,97 & 19,53 & 19,53 & 14,17 & 18,31 \\
\hline \multirow{7}{*}{2} & All the electrolyte solution must be an ionic compound & 22,58 & 9,38 & 15,63 & 30,00 & 18,90 \\
\hline & $\begin{array}{l}\mathrm{HCl} \text { and } \mathrm{NaCl} \text { is an electrolyte because } \mathrm{HCl} \text { is a strong acid } \\
\text { and } \mathrm{NaCl} \text { formed from strong acid and strong base }\end{array}$ & 19,35 & 9,38 & 84,38 & 36,67 & 37,01 \\
\hline & $\begin{array}{l}\mathrm{NaOH} \text { and } \mathrm{HNO}_{3} \text { is an electrolyte because it can totally } \\
\text { dissolved in water }\end{array}$ & 0,00 & 0,00 & 3,13 & 3,33 & 1,57 \\
\hline & $\begin{array}{l}\mathrm{NaOH} \text { and } \mathrm{HNO}_{3} \text { is an electrolyte because } \mathrm{NaOH} \text { is a strong } \\
\text { base and } \mathrm{HNO}_{3} \text { is a strong acid }\end{array}$ & 0,00 & 3,13 & 15,63 & 6,67 & 6,30 \\
\hline & $\mathrm{HCl}$ is an electrolyte solution because $\mathrm{HCl}$ is a strong acid & 32,26 & 3,13 & 31,25 & 26,67 & 22,83 \\
\hline & $\begin{array}{l}\mathrm{HCl} \text { is an electrolyte solution because between hydrogen } \\
\text { atom and } \mathrm{Cl} \text { atom has a large electronegativity difference }\end{array}$ & 22,58 & 0,00 & 18,75 & 10,00 & 12,60 \\
\hline & Mean & 16,13 & 4,17 & 28,13 & 18,89 & 16,54 \\
\hline \multirow{4}{*}{3} & Only $\mathrm{NaCl}$ solution (aqueous) can conduct electricity & 9,68 & 15,63 & 25,00 & 13,33 & 15,75 \\
\hline & An ionic compound can conduct electricity in all phases & 12,90 & 25,00 & 37,50 & 26,67 & 25,20 \\
\hline & $\begin{array}{l}\text { A covalent compound is an electrolyte in liquid and aqueous } \\
\text { phases }\end{array}$ & 9,68 & 3,13 & 12,50 & 3,33 & 7,09 \\
\hline & Mean & 10,75 & 14,59 & 25,00 & 14,44 & 16,01 \\
\hline
\end{tabular}

The results showed us that in the concept of electrolyte and non- electrolyte solutions, some students have some alternative conceptions, like an electrolyte solution which is a solution which can conduct electricity because there are ions that can move freely. Some students answered that the electrolyte solution is a solution which can produce a charged compound $(20,47 \%)$. Other students stated that the electrolyte solution is a solution that has a large potential difference $(13,39 \%)$, and some students stated that an electrolyte solution should be able to turn on a lamp $(26,77 \%)$ and can produce gases at electrodes $(12,60 \%)$. These results suggest that students have an inappropriate conception about the basic concepts of electrolyte solutions.

In addition, in the chemical bonding concept and its impact on electricity, some students have alternative conceptions. As much as $18,9 \%$ of students assumed that all the electrolyte solution must be an ionic compound. Some students also do not understand how to determine the nature of the electrolyte of a compound based on its bonds. Some students only remembered examples of compounds that are elctrolyte or non-electrolyte without the reasons. It can be seen that the greatest alternative conceptions were found in students' understanding that $\mathrm{HCl}$ is an electrolyte because it is a strong acid and $\mathrm{NaCl}$ is also electrolyte because it consists of a mixture of a strong acid and a strong bases (37\%). These alternative conceptions were obtained from the sample given in the class, so that students could memorize and did not know the explanation. In addition, the students also stated that $\mathrm{HCl}$ is an electrolyte solution because between $\mathrm{H}$ and $\mathrm{Cl}$ there is a large electronegativity difference $(12,6 \%)$. This alternative conception can be caused by a lack of students' understanding of the chemical concepts they learned earlier. Thus, to reduce alternative conceptions in chemical concepts, teachers need to check students' understanding of prior knowledge, especially the concepts that are related to the new concept.

The third concept is the phase and its impact on electricity. Some students have some alternative conceptions for the phase and its impact on electricity. Some students assumed that only $\mathrm{NaCl}$ in solution (aqueous phase) can conduct electricity $(15,75 \%)$, some students stated that an ionic compound can conduct electricity in all phases $(25,20 \%)$, and some students assumed that a covalent compound is an electrolyte in liquid and aqueous phases (7,09\%). These students' alternative conception does not match with the existing scientific conception of phase and electricity. Some students who have these alternative conceptions know about the phases of the compounds, but they are unfamiliar with the use of phases in a chemical context. This happens because their teachers rarely involved the phases in explaining the chemical contexts so that students know but 
are not familiar with the phases and their effects on electricity. It is important for the teacher to use the correct language, terms, and contexts, because it can cause students to have alternative conceptions.

Based on the results of this study, the topics of electrolyte and non-electrolyte solutions have some problems for students. Therefore, it is necessary to review these concepts at different levels to reinforce students' conceptions by using appropriate learning strategies. In addition, teachers should be familiar with the way students develop their understanding of electrolyte and non-electrolyte topics. The findings of this study indicate that the students' alternative conceptions can be obtained through students' experiences and observations, the terms used by the teacher and students, the book, or the way students develop their knowledge based on previous theories [30]. Thus, to prevent students' misconceptions, teachers need to know the sources of alternative conceptions that may occur among students, and how to prevent them. Research related to chemical education discusses the students' alternative conceptions on various chemical topics, as well as some existing diagnostic instruments can be developed and integrated in teacher education programs, so as to facilitate the improvement of understanding of chemistry concepts of student in the learning process.

\section{Conclusions}

By viewing the results of two-tier diagnostic tests and in-depth interviews of the students, useful conclusions can be drawn that some students had an appropriate conception about electrolyte concepts, chemical bonding, and phases of compounds. Besides the appropriate concept, some students also had an alternative conception. Based on the interviews, the students had some alternative conceptions because they were not familiar with using the phase notation so they do not understand the meaning of phases of compound and its impact on electricity. Furthermore, the students' alternative conceptions can be obtained through students' experiences and observations, the terms used by the teacher and students, the book, or the way students develop their knowledge based on previous theories. Teachers need to know the sources of alternative conceptions that may occur among students, and how to prevent students' misconceptions. As a teacher, we also should inform the students the appropriate concept using the true macroscopic, submicroscopic, and symbolic representations of chemistry, so the students can understand the concept they learn in chemistry.

Such as an electrolyte solution is a solution which can produce a charged compound $(20,47 \%)$, an electrolyte solution has a large potential difference (13,39\%), electrolyte solutions should be able to turn on a lamp $(26,77 \%)$, an electrolyte solution is a solution which can react with electrodes and produce gasses $(12,60 \%)$, all the electrolyte solution must be an ionic compound (18,90\%), $\mathrm{HCl}$ and $\mathrm{NaCl}$ are electrolytes because $\mathrm{HCl}$ is a strong acid and $\mathrm{NaCl}$ is formed from a strong acid and a strong base $(37,01 \%), \mathrm{NaOH}$ and $\mathrm{HNO}_{3}$ are electrolytes because they can totally be dissolved in water $(1,57 \%), \mathrm{NaOH}$ and $\mathrm{HNO}_{3}$ are electrolytes because $\mathrm{NaOH}$ is a strong base and $\mathrm{HNO}_{3}$ is a strong acid $(6,30 \%), \mathrm{HCl}$ is an electrolyte solution because $\mathrm{HCl}$ is a strong acid $(22,83 \%), \mathrm{HCl}$ is an electrolyte solution because between hydrogen atoms and $\mathrm{Cl}$ atoms there is a large electronegativity difference $(12,60 \%)$, only $\mathrm{NaCl}$ solution (aqueous) can conduct electricity $(15,75 \%)$, an ionic compound can conduct electricity in all phases $(25,20 \%)$, and a covalent compound is an electrolyte in liquid and aqueous phases $(7,09 \%)$. Based on the interviews, the students had some alternative conceptions because they were not familiar with using the phase notation so they do not understand the meaning of phases of compound and its impact in electricity. As a teacher, we should inform the students the appropriate concept using the true macroscopic, submicroscopic, and symbolic representations of chemistry, so the students can better understand chemistry.

\section{REFERENCES}

[1] Y. J. Dori, S. Rodrigues, and S. Schanze, "How to Promote Chemistry Learning Through The Use of ICT," in Teaching Chemistry - A Studybook, vol. 24, no. 4, I. Eilks and A. Hofstein, Eds. Rotterdam: Sense Publishers, 2013, pp. 423425 .

[2] T. Koballa, W. Gräber, D. C. Coleman, and A. C. Kemp, "Prospective gymnasium teachers' conceptions of chemistry learning and teaching," Int. J. Sci. Educ., vol. 22, no. 2, pp. 209-224, 2000.

[3] Y. Rahmawati and A. Ridwan, "Empowering Students' Chemistry Learning: The Integration of Ethnochemistry in Culturally Responsive Teaching," Bulg. J. Sci. Educ., vol. 26, no. 6, pp. 813-830, 2017.

[4] J. K. Gilbert, O. De Jong, R. Justi, D. F. Treagust, and J. H. Van Driel, Chemical Education: Towards Research-based Practice. New York: Kluwer Academic Publishers, 2003.

[5] A. H. Johnstone, "Symposium on fievolution and Evolution in Chemical $€$ ducation The Development of Chemistry Teaching," Forum Fam. Plan. West. Hemisph., vol. 70, no. 9, pp. 701-705, 1993.

[6] D. F. Treagust, "Development and use of diagnostic tests to evaluate students' misconceptions in science," Int. J. Sci. Educ., vol. 10, no. 2, pp. 159-169, 1988.

[7] H. Özmen, "Some Student Misconceptions in Chemistry: A Literature Review of Chemical Bonding," J. Sci. Educ. Technol., vol. 13, no. 2, pp. 147-159, 2004.

[8] P. J. Garnett, P. J. Garnett, and M. W. Hackling, "Students' alternative conceptions in chemistry: A review of research 
and implications for teaching and learning," Stud. Sci. Educ., vol. 25, no. 1, pp. 69-96, 1995.

[9] J. K. Gilbert and D. M. Watts, "Studies in Science Education Concepts, Misconceptions and Alternative Conceptions : Changing Perspectives in Science Education," no. May 2013, pp. 37-41, 2013.

[10] P. J. Garnett and D. F. Treagust, "Conceptual difficulties experienced by senior high school students of electrochemistry: Electric circuits and oxidation reduction equations," J. Res. Sci. Teach., vol. 29, no. 2, pp. 121-142, 1992.

[11] M. J. Sanger and T. J. Greenbowe, "Addressing student misconceptions concerning electron flow in aqueous solutions with instruction including computer animations and conceptual change strategies," Int. J. Sci. Educ., vol. 22, no. 5 , pp. 521-537, 2000.

[12] C. Y. Tsui and D. Treagust, "Evaluating secondary students' scientific reasoning in genetics using a two-tier diagnostic instrument," Int. J. Sci. Educ., vol. 32, no. 8, pp. 1073-1098, 2010.

[13] Y. Rahmawati, R. Koul, and D. Fisher, "Teacher-Student Dialogue: Transforming Teacher Interpersonal Behaviour and Pedagogical Praxis through Co-Teaching and Co-Generative Dialogue," Learn. Environ. Res. Int. J., vol. 18, no. 3, pp. 393-408, 2014.

[14] A. L. Chandrasegaran, D. F. Treagust, and M. Mocerino, "The development of a two-tier multiple-choice diagnostic instrument for evaluating secondary school students' ability to describe and explain chemical reactions using multiple levels of representation," Chem. Educ. Res. Pract., vol. 8, no. 3, pp. 293-307, 2007.

[15] N. K. Goh and L. S. Chia, "Students ' Learning Difficulties on Covalent Bonding and Structure Concepts," Teach. Learn., vol. 12, no. 2, pp. 58-65, 1999.

[16] C. Tüysüz, "Development of two-tier diagnostic instrument and assess students' understanding in chemistry," Sci. Res. Essays, vol. 4, no. 6, pp. 626-631, 2009.

[17] J. M. Nyachwaya, A. R. Mohamed, G. H. Roehrig, N. B. Wood, A. L. Kern, and J. L. Schneider, "The development of an open-ended drawing tool: An alternative diagnostic tool for assessing students' understanding of the particulate nature of matter," Chem. Educ. Res. Pract., vol. 12, no. 2, pp. 121-132, 2011.

[18] J. R. Baird, P. J. Fensham, R. F. Gunstone, and R. T. White, "The importance of reflection in improving science teaching and learning," J. Res. Sci. Teach., vol. 28, no. 2, pp. 163-182, 1991.

[19] M. J. Sanger, 'Evaluating students' conceptual understanding of balanced equations and stoichiometric ratios using a particulate drawing," J. Chem. Educ., vol. 82, no. 1, pp. 131-134, 2005.

[20] J. W. Renner, M. R. Abraham, E. B. Grzybowski, and E. A. Marek, "Understandings and misunderstandings of eighth graders of four physics concepts found in textbooks," J. Res. Sci. Teach., vol. 27, no. 1, pp. 35-54, 1990.

[21] B. K. Bayrak, "Using Two-Tier Test to Identify Primary Students' Conceptual Understanding and Alternative
Conceptions in Acid Base," Mevlana Int. J. Educ., vol. 3, no. 2, pp. 19-26, 2013.

[22] R. H. Petrucci, F. G. Herring, S. S. Perry, J. D. Madura, and C. Bissonnette, General Chemistry: Principles and Modern Applications, 10th ed. Toronto: Canada: Pearson Canada Inc, 2011.

[23] M. A. Teichert, L. T. Tien, S. Anthony, and D. Rickey, "Effects of context on students' molecular-level ideas," Int. J. Sci. Educ., vol. 30, no. 8, pp. 1095-1114, 2008.

[24] B. Rittle-Johnson, R. S. Siegler, and M. W. Alibali, "Developing conceptual understanding and procedural skill in mathematics: An iterative process," J. Educ. Psychol., vol. 93, no. 2, pp. 346-362, 2001.

[25] Z. Haláková and M. Prokša, "Two Kinds of Conceptual Problems in Chemistry Teaching," J. Chem. Educ., vol. 84, no. 1, p. 172, 2007.

[26] T. A. Holme, C. J. Luxford, and A. Brandriet, "Defining Conceptual Understanding in General Chemistry," J. Chem. Educ., vol. 92, no. 9, pp. 1477-1483, 2015.

[27] A. G. Harrison and D. F. Treagust, "Learning about Atoms Molecules, and Chemical Bonds: A Case Study of Multiple-Model Use in Grade 11 Chemistry," pp. 352-381, 1999.

[28] S. L. Bretz, "Novak's Theory of Education: Human Constructivism and Meaningful Learning," J. Chem. Educ., vol. 78, no. 8, p. 1107, 2009.

[29] R. Duit and D. F. Treagust, "Conceptual change: A powerful framework for improving science teaching and learning," Int. J. Sci. Educ., vol. 25, no. 6, pp. 671-688, 2003.

[30] H. D. Barke, A. Hazari, and S. Yitbarek, Misconception in Chemistry:A Addressing Perceptions in Chemical Education. Berlin: Springer, 2009. 